\title{
Accumulated glutamate levels in the synaptic vesicle are not maintained in the absence of active transport
}

\author{
Martha D. Carlson ${ }^{1}$ and Tetsufumi Ueda ${ }^{1-3}$ \\ Departments of 'Pharmacology and ${ }^{2}$ Psychiatry, and ${ }^{3}$ Mental Health Research Institute, The University of \\ Michigan, Ann Arbor, MI (U.S.A.)
}

(Received 6 September 1989; Revised version received 14 November 1989; Accepted 15 November 1989)

Key words: Synaptic vesicle; ATP-dependent uptake; Electrochemical proton gradient; Steady-state glutamate level; Glutamate translocator

We have investigated factors which may affect accumulated glutamate levels in synaptic vesicles and glutamate efflux. Agents which dissipate the electrochemical proton gradient resulted in a rapid reduction of steady-state vesicular glutamate levels, which was prevented by $N$-ethylmaleimide. Glutamate efflux was found to occur even in the presence of an electrochemical proton gradient, but was effectively inhibited by $N$-ethylmaleimide. These results suggest that accumulated glutamate levels in synaptic vesicles are not maintained unless glutamate is taken up continuously by an active transport mechanism, and they could provide an explanation for the lack of convincing evidence for the enrichment of endogenous glutamate in isolated synaptic vesicles.

Glutamate is widely recognized as the strongest candidate for an excitatory amino acid neurotransmitter $[4,7,25,29,30]$, and its role in neuronal plasticity and various neurological diseases has been implicated $[3,5,9,20,26]$. In recent years, evidence has accumulated that glutamate is taken up into isolated synaptic vesicles in an ATPdependent manner $[2,6,8,13,19,23,24]$, supporting the neurotransmitter role of glutamate. The vesicular glutamate uptake is driven by an electrochemical proton gradient, generated by a Mg-ATPase located in the vesicle membrane $[19,24,27]$. Despite the evidence for the active transport system for glutamate in the synaptic vesicle membrane, earlier investigations have failed to demonstrate that this amino acid is stored in isolated synaptic vesicles at high concentrations [15, 17]. However, immunocytochemical studies have suggested that glutamate is present in high concentrations in synaptic vesicles in certain nerve endings [28]. These apparently discrepant lines of evidence suggest that the glutamate accumulated in synaptic vesicles may not be maintained during the synaptic vesicle isolation. In an effort to understand the storage mechanism for vesicular glutamate, we have examined factors

Correspondence: T. Ueda, Mental Health Research Institute, The University of Michigan, 205 Washtenaw Place, Ann Arbor, MI 48109, U.S.A. 
which affect accumulated glutamate levels in synaptic vesicles. An account of this work has been reported previously [1].

Synaptic vesicles were prepared from rat cerebrum as described by Kish and Ueda [14] and resuspended in Solution $B(0.32 \mathrm{M}$ sucrose, $1 \mathrm{mM}$ dithiothreitol, $1 \mathrm{mM}$ $\mathrm{NaHCO}_{3}$ ). This vesicle preparation, referred to as $\mathrm{RCSV}$, was used in all of the experiments to be described here. The synaptic vesicle preparation ( $50 \mu \mathrm{g}$ protein) was incubated at $30^{\circ} \mathrm{C}$ in a solution (final volume, $100 \mu \mathrm{l}$ ) containing $10 \mathrm{mM}$ HEPES (pH 7.4), $0.25 \mathrm{M}$ sucrose, $4 \mathrm{mM} \mathrm{KCl}, 4 \mathrm{mM} \mathrm{MgSO}_{4}, 2 \mathrm{mM}$ L-aspartate, $50 \mu \mathrm{M}$ L- $\left[{ }^{3} \mathrm{H}\right]$ glutamate $(0.4 \mathrm{Ci} / \mathrm{mmol})$ and $1 \mathrm{mM}$ Tris-ATP, essentially as described previously [24]. After 10 min incubation for glutamate uptake, test agents were added in $10 \mu \mathrm{l}$, and incubation was allowed to continue for various periods of time. The incubation was terminated by the addition of $2 \mathrm{ml}$ of ice-cold $0.15 \mathrm{M} \mathrm{KCl}$, as described previously [24]. Each assay was carried out in duplicate, and the results were expressed as the amount ( $\mathrm{pmol} / \mathrm{mg}$ ) of $\left[{ }^{3} \mathrm{H}\right]$ glutamate retained, with the average value and the range of variation. Protein was determined according to Lowry et al. [16] with bovine serum albumin as standard.

Fig. 1A demonstrates that glutamate is taken up into the synaptic vesicle preparation in an ATP-dependent manner. The uptake reaches a steady-state level around $10 \mathrm{~min}$. Previous studies have indicated that glutamate uptake is driven by an electrochemical proton gradient generated by a proton-pump Mg-ATPase in the synaptic vesicle membrane $[19,24,27]$. To determine whether the membrane potential and transmembrane $\mathrm{pH}$ gradient are involved in maintaining steady-state levels of glutamate in the synaptic vesicle, we examined the effect of the proton ionophore FCCP and the $\mathrm{K}^{+} / \mathrm{H}^{+}$exchanger nigericin on the steady-state levels of glutamate in synaptic vesicles. FCCP and nigericin have been shown to dissipate the membrane potential and transmembrane $\mathrm{pH}$ gradient, respectively, in chromaffin granule and highly
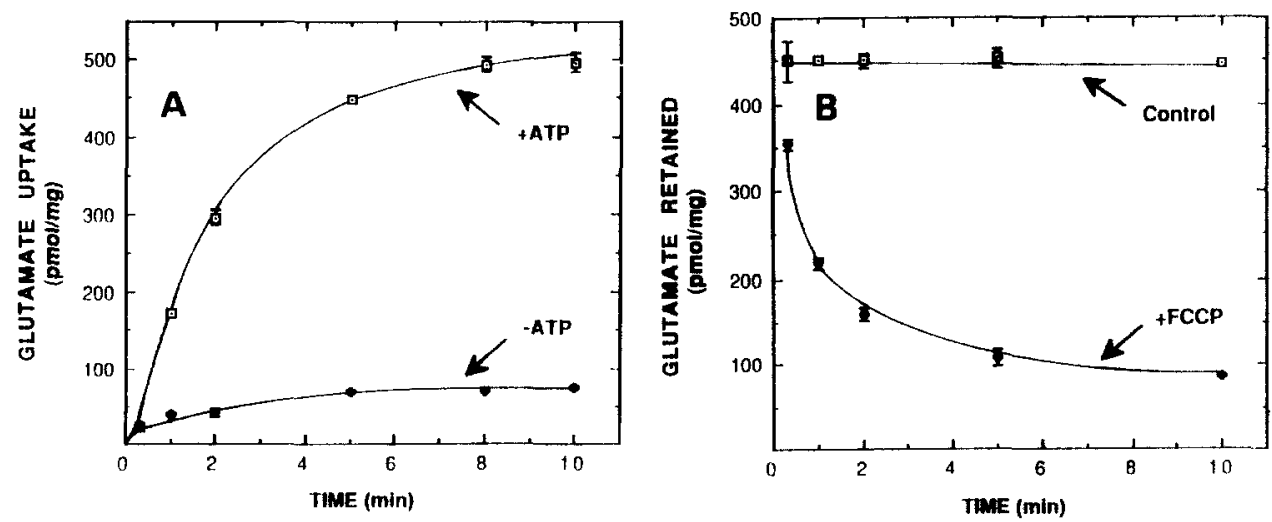

Fig. 1. Time course of vesicular glutamate uptake and the effect of FCCP on the steady-state level of glutamate. A: synaptic vesicles were incubated in the presence (D) or absence ( ) of ATP and filtered at the various times indicated. B: synaptic vesicles were preloaded for $10 \mathrm{~min}$ with $\left[{ }^{3} \mathrm{H}\right]$ glutamate in the presence of ATP. At $10 \mathrm{~min}$, either $0.5 \%$ dimethyl sulfoxide $\left(\mathrm{Me}_{2} \mathrm{SO}\right.$ ) alone (control) (Q) or $10 \mu \mathrm{M} \mathrm{FCCP} \mathrm{(in} 0.5 \%$ $\mathrm{Me}_{2} \mathrm{SO}$ ) ( $\$$ ) were added in small volume $(10 \mu \mathrm{l} / 100 \mu \mathrm{l}$ assay vol), and the samples were filtered at the various times indicated. $\mathrm{Me}_{2} \mathrm{SO}(0.5 \%)$ alone had no effect on glutamate uptake activity. 
purified synaptic vesicle preparations $[10-12,19,27]$, as well as in the partially purified vesicle preparation used in this study (data not shown). Fig. 1B shows that the addition of FCCP $(10 \mu \mathrm{M})$ caused a rapid reduction of the steady-state glutamate levels. Nearly identical results were also obtained with nigericin (data not shown). These results suggest that the existence of an electrochemical proton gradient across the vesicular membrane is required in order to maintain steady-state levels of vesicular glutamate.

Fig. 2 shows that the effects of FCCP and nigericin on steady-state glutamate levels were blocked by pretreatment with the sulfhydryl-modifying agent $N$-ethylmaleimide (NEM, $500 \mu \mathrm{M}$ ). In experiments not shown, we have examined the effect of FCCP on the membrane potential, which was generated upon addition of Mg-ATP, using the voltage-sensitive fluorescent dye oxonal $\mathrm{V}$. We have repeatedly observed that treatment $\left(2 \mathrm{~min}\right.$ at $\left.30^{\circ} \mathrm{C}\right)$ of the synaptic vesicles with $\mathrm{NEM}(500 \mu \mathrm{M})$, after the membrane potential was generated, did not prevent the ability of FCCP to dissipate the membrane potential. It may be noted that the steady-state glutamate level was hardly affected by NEM, despite its demonstrated inhibitory effects on glutamate uptake into synaptic vesicles [24] and on the proton pump ATPase [22]. These results are in accord with the notion that NEM blocks glutamate efflux regardless of electrochemical proton gradients.

In order to examine the effect of NEM and FCCP more directly on the efflux process, synaptic vesicles, which had been preloaded with $\left[{ }^{3} \mathrm{H}\right]$ glutamate in the presence of ATP, were treated with NEM, then diluted 20 -fold into an efflux medium devoid

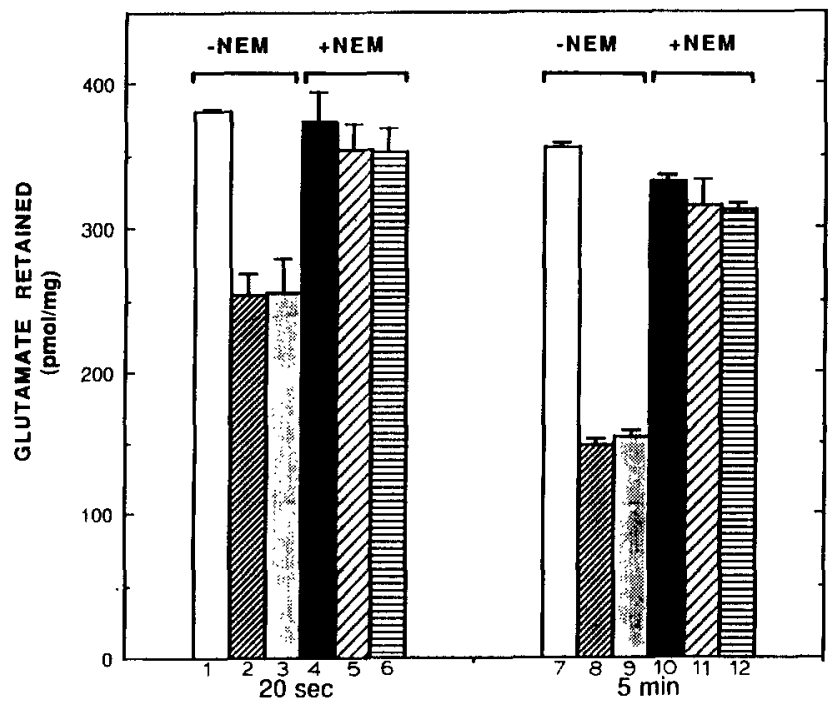

Fig. 2. Effect of NEM on steady-state vesicular glutamate levels. After synaptic vesicles were preloaded for $10 \mathrm{~min}$ with [ $\left.{ }^{3} \mathrm{H}\right]$ glutamate in the presence of ATP, $\mathrm{H}_{2} \mathrm{O}$ or $500 \mu \mathrm{M}$ NEM were added in small volume, and the suspension was incubated for an additional $5 \mathrm{~min}$ at $30^{\circ} \mathrm{C}$. After the 5 min treatment with $\mathrm{H}_{2} \mathrm{O}$ (1-3, 7-9), or NEM (4-6,10-12), either $\mathrm{H}_{2} \mathrm{O}(1,4,7,10), 10 \mu \mathrm{M}$ FCCP $(2,5,8,11)$, or $20 \mu \mathrm{M}$ nigericin $(3,6,9,12)$ were added in small volume $(10 \mu \mathrm{l} / 100 \mu \mathrm{l}$ assay vol $)$, and the samples were filtered at the times indicated. 
of ATP and glutamate, with or without FCCP, and further incubated. Fig. 3 demonstrates that glutamate efflux does occur at a significant rate after the 20 -fold dilution. Under these conditions, the original electrochemical proton gradient was found to be maintained for at least $10 \mathrm{~min}$ (data not shown). The significant efflux which occurs in the presence of electrochemical proton gradients was stimulated by FCCP. Interestingly, NEM pretreatment blocked the glutamate efflux regardless of the presence of FCCP.

The results presented here indicate that the existence of an electrochemical proton gradient across the synaptic vesicle membrane is required in order to maintain steady-state glutamate levels. The experiment shown in Fig. 3 indicates that there is a rapid efflux of glutamate from these synaptic vesicles, even in the presence of electrochemical proton gradients. The rate of glutamate efflux was found to be dependent upon the glutamate concentration gradient across the vesicle membrane (Carlson, M.D. and Ueda, T., in preparation). These observations suggest that the vesicular storage mechanism of glutamate differs, at least in part, from that for catecholamines and acetylcholine $[18,21]$. These amine neurotransmitters are not lost from the vesicles even if there is a large concentration gradient across the vesicle membrane, as long as the intravesicular $\mathrm{pH}$ is in the acidic range [18] or an electrochemical proton

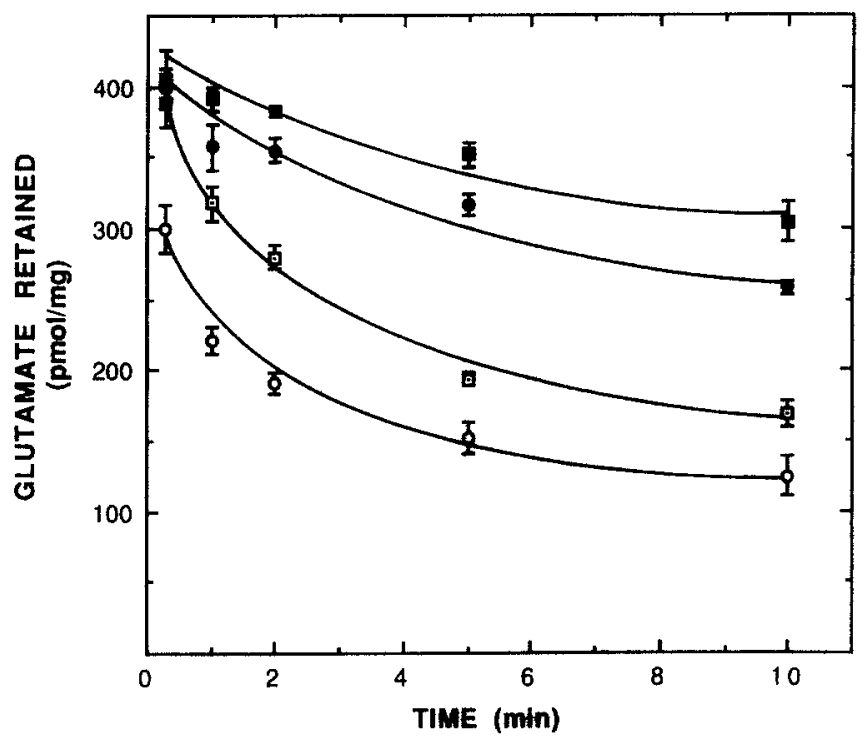

Fig. 3. Effect of NEM and FCCP on glutamate efflux from preloaded synaptic vesicles. Synaptic vesicles were preloaded with [ ${ }^{3} \mathrm{H}$ ]glutamate in the presence of ATP. At $10 \mathrm{~min}, \mathrm{H}_{2} \mathrm{O}(\mathrm{O}, \mathrm{O})$ or $500 \mu \mathrm{M} \mathrm{NEM}$ $(\square, 0)$ were added in small volume $(10 \mu \mathrm{l} / 100 \mu \mathrm{l}$ assay vol), and the mixtures were incubated for an additional $5 \mathrm{~min}$ at $30^{\circ} \mathrm{C}$. After the $5 \mathrm{~min}$ incubation, $1.9 \mathrm{ml}$ of a solution (prewarmed at $30^{\circ} \mathrm{C}$ ) containing the standard glutamate uptake mixture were addod, except for the omission of ATP and ghtmate and for the inclusion of none (control, (Q), $10 \mu \mathrm{M}$ FCCP (O), $500 \mu \mathrm{M} \mathrm{NEM} \mathrm{(2),} \mathrm{or} 10 \mu \mathrm{M} \mathrm{FCCP}+500$ $\mu \mathrm{M}$ NEM ( $)$, and the incubation was allowed to continue for various periods of time. The chax was terminated by the addition of $\mathrm{KCl}$ followed by filtration. The addition of the $\mathrm{KCl}$ solution and the immediate filtration step altogether normally took approximately $20 \mathrm{~s}(0.3 \mathrm{~min})$. 
gradient is maintained [21]. Although glutamate efflux does occur in the presence of an electrochemical proton gradient, the efflux is stimulated by FCCP. This suggests that an electrochemical proton gradient, particularly the membrane potential, may impose a partial kinetic barrier to glutamate efflux. Therefore, the effect of FCCP in Fig. $1 \mathrm{~B}$ is likely due to an inhibition of uptake and a facilitation of efflux.

The inhibitory effect of NEM on the efflux of glutamate suggests that the efflux is carrier-mediated. This notion is further supported by the observations that glutamate efflux is temperature-dependent and that the glutamate efflux is reduced by a competitive inhibitor of glutamate uptake (Carlson, M.D. and Ueda, T., in preparation). The ability of NEM to achieve this inhibitory effect regardless of the presence of FCCP suggests that a cysteine sulfhydryl group is involved in a mechanism distinct from that which involves electrochemical proton gradients. Data not shown also suggest that a sulfhydryl group of the glutamate translocator is critical for the uptake (Naito and Ueda, unpublished observations). Thus, it is plausible that a cysteine sulfhydryl group plays a role in regulating steady-state glutamate levels in the synaptic vesicle in vivo.

The data presented in this study predict that rat brain synaptic vesicles would be depleted of a major portion of endogenously accumulated glutamate during the vesicle isolation, which is normally carried out under conditions in which the electrochemical proton gradient is not maintained. These considerations could provide an explanation for the apparent difficulty in demonstrating the enrichment of endogenous glutamate in isolated synaptic vesicles $[15,17]$.

We acknowledge Drs. Joel Tabb and Phil Kish for their valuable comments on this manuscript. This study was supported by National Science Foundation BNS8207999 and National Institutes of Health NS 26884.

1 Carlson, M.D. and Ueda, T., Glutamate efflux from synaptic vesicles, J. Neurochem., 52 (1989) Suppl. S67C (abstr.).

2 Carlson, M.D., Kish, P.E. and Ueda, T., Characterization of the solubilized and reconstituted ATPdependent vesicular glutamate uptake system, J. Biol. Chem., 264 (1989) 7369-7376.

3 Collingridge, G.L. and Bliss, T.V.P., NMDA receptors - their role in long-term potentiation, Trends Neurosci., 10 (1987) 288-293.

4 Cotman, C.W., Monaghan, D.T., Ottersen, O.P. and Storm-Mathisen, J., Anatomical organization of excitatory amino acid receptors and their pathways, Trends Neurosci., 10 (1987) 273-279.

5 Cotman, C.W., Bridges, R.J., Taube, J.S., Clark, A.S., Geddes, J.W. and Monaghan, D.T., The role of the NMDA receptor in central nervous system plasticity and pathology, J. NIH Res., 1 (1989) 65-74.

6 Fischer-Bovenkerk, C., Kish, P.E. and Ueda, T., ATP-dependent glutamate uptake into synaptic vesicles from cerebellar mutant mice, J. Neurochem., 51 (1988). 1054-1059.

7 Fonnum, F., Glutamate: a neurotransmitter in mammalian brain, J. Neurochem., 42 (1984) 1-11.

8 Fyske, E.M., Christensen, H. and Fonnum, F., Comparison of the properties of $\gamma$-aminobutyric acid and L-glutamate uptake into synaptic vesicles isolated from rat brain, J. Neurochem., 52 (1989) 946-951.

9 Greenamyre, J.T., The role of glutamate in neurotransmission and in neurologic disease, Arch. Neurol., 43 (1986) 1058-1063.

$10 \mathrm{Holz}$, R.W., Evidence that catecholamine transport into chromaffin vesicles is coupled to vesicle membrane potential, Proc. Natl. Acad. Sci. U.S.A., 75 (1978) 5190-5194. 
11 Johnson, R.G. and Scarpa, A., Protonmotive force and catecholamine transport in isolated chromaffin granules, J. Biol. Chem., 254 (1979) 3750-3760.

12 Johnson, R.G., Carlson, N.J. and Scarpa, A., $\Delta \mathrm{pH}$ and catecholamine distribution in isolated chromaffin granules, J. Biol. Chem., 253 (1978) 1512-1521.

13 Kish, P.E., Kim, S.Y. and Ueda, T., Ontogeny of glutamate accumulating activity in rat brain synaptic vesicles, Neurosci. Lett., 97 (1989) 185-190.

14 Kish, P.E. and Ueda, T., Glutamate accumulation into synaptic vesicles. In S. and B. Fleischer (Eds.), Methods in Enzymology, Biomembranes, Part M: Biological Transport, Vol. 4, Cellular and Sub-cellular Transport: Eukaryotic (Non-Epithelial) Cells, Academic Press, New York, in press.

15 Kontro, P., Marnela, K.-M. and Oja, S.S., Free amino acids in the synaptosome and synaptic vesicle fractions of different bovine brain areas, Brain Res., 184 (1980) 129-141.

16 Lowry, O.H., Rosebrough, N.J., Farr, A.L. and Randall, R.J., Protein measurement with Folin phenol reagent, J. Biol. Chem., 193 (1951) 265-275.

17 Mangan, J.L. and Whittaker, V.P., The distribution of free amino acids in subcellular fractions of guinea-pig brain, Biochem. J., 98 (1966) 128-137.

18 Maron, R., Stern, Y., Kanner, B.I. and Schuldiner, S., Functional asymmetry of the amine transporter from chromaffin granules, J. Biol. Chem., 258 (1983) $11476-11481$.

19 Maycox, P.R., Deckwerth, T., Hell, J.W. and Jahn, R., Glutamate uptake by brain synaptic vesicles. J. Biol. Chem., 263 (1988) 1542315428.

20 Meldrum, B., Possible therapeutic applications of antagonists of excitatory amino acid neurotransmitters, Clin. Sci., 68 (1985) 113-122.

21 Michaelson, D.M. and Angel, I., Determination of $\Delta \mathrm{pH}$ in cholinergic synaptic vesicles: its effect on storage and release of acetylcholine, Life Sci., 27 (1980) 39.44.

22 Moriyama, Y. and Nelson, N., The purified ATPase from chromaffin granule membranes is an aniondependent proton pump, J. Biol. Chem., 262 (1987) 9175-9180.

23 Naito, S. and Ueda, T., Adenosine triphosphate-dependent uptake of glutamate into Protein I-associated synaptic vesicles, J. Biol. Chem., 258 (1983) 696-699.

24 Naito, S. and Ueda, T., Characterization of glutamate uptake into synaptic vesicles, J. Neurochem., 44 (1985) 99-109.

25 Nicholls, D.G., Release of glutamate, aspartate and $\gamma$-aminobutyric acid from isolated nerve terminals, J. Neurochem., 52 (1989) 331-341.

26 Rothman, S.M. and Olney, J.W., Excitotoxicity and the NMDA receptor, Trends Neurosci., 10 (1987) 299-302.

27 Shioi, J., Naito, S. and Ueda, T., Glutamate uptake into synaptic vesicles of bovine cerebral cortex and electrochemical potential difference of proton across the membrane, Biochem. J., 258 (1989) $499-504$.

28 Storm-Mathisen, J., Leknes, A.K., Bore, A.T., Vaaland, J.L., Edminson, P., Haug, F.-M.S. and Ottersen, O.P., First visualization of glutamate and GABA in neurons by immunocytochemistry, Nature (Lond.), 301 (1983) 517-520.

29 Ueda, T., Glutamate transport in the synaptic vesicle. In P.J. Roberts, J. Storm-Mathisen and H.F Bradford (Eds.), Excitatory Amino Acids, Macmillan, London, 1986, pp. 173-195.

30 Watkins, J.C. and Evans, R.H., Excitatory amino acid transmitters, Annu. Rev. Pharmacol. Toxicol., 21 (1981) 165-204. 